\title{
Dsophageal Ulcer Due to Ectopic Pancreatic Tissue: A Case Report
}

\author{
Pezhman Alavinejad ${ }^{1, *}$, Amir Hossein Sina ${ }^{2}$, Damoon Dehnavi ${ }^{3}$, Morteza Nayebi ${ }^{3}$
}

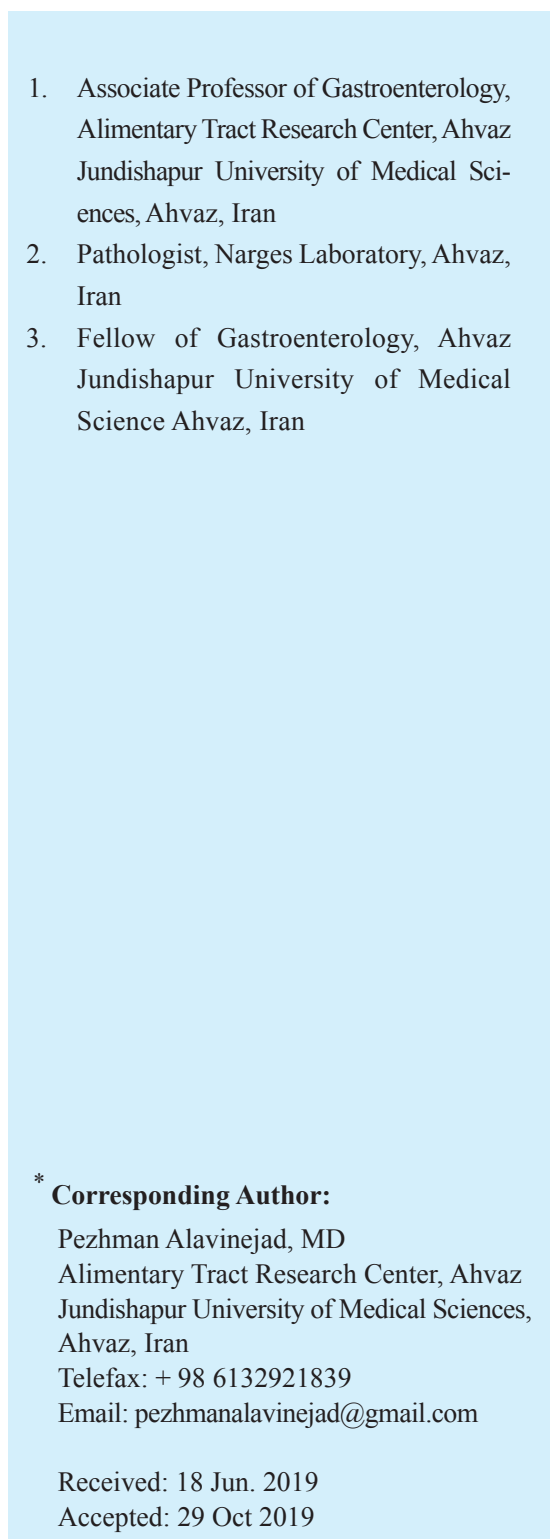

Accepted: 29 Oct 2019

\section{ABSTRACT}

Heterotopic pancreatic tissue, known as pancreatic rest, is a pancreatic tissue that lacks anatomic and vascular continuity with the main body of the pancreas. Common locations for this tissue include the stomach, duodenum, jejunum, Meckel diverticulum, and ileum. In this report, we present a case of a patient whose pancreatic rest was diagnosed primarily during the investigation of dysphagia with solid foods and it was located in the mid esophagus as an unusual location.

\section{KEYWORDS:}

Esophageal Ulcer, Ectopic Pancreatic, Dysphagia, Esophagus

Please cite this paper as:

Alavinejad P, Sina AH, Dehnavi D, Nayebi M. Esophageal Ulcer Due to Ectopic Pancreatic Tissue: A Case Report. Middle East J Dig Dis 2020;12:45-47. doi: 10.15171/mejdd.2020.163.

\section{CASE REPORT}

A 70-year-old man was referred to our outpatient clinic with the complaint of odynophagia and epigastric discomfort. The patient was referred for upper endoscopy. During endoscopy, a superficial ulcer was found in the mid esophagus without any raising borders or central umbilication (figure 1) and the pathological report of the biopsy samples was in favor of active esophagitis. Treatment with pantoprazole was started and the patient was discharged.

Two months later and during the follow-up, he complained of no improvement and was referred for the second endoscopy. During the second endoscopy, the previous ulcer was seen without any decrease in size and the endoscopist obtained deeper biopsy samples with the bite on bite technique. This time, the pathologist reposted the specimen as pancreatic rest containing both acini and ducts (figure 2). Treatment with supplementary pancreatic enzymes (Creon 25000 TDS) commenced in addition to prescribing pantoprazole and the patient was discharged. In his follow-up during the next 6 months, all his symptoms were resolved and his medication tapered gradually. 


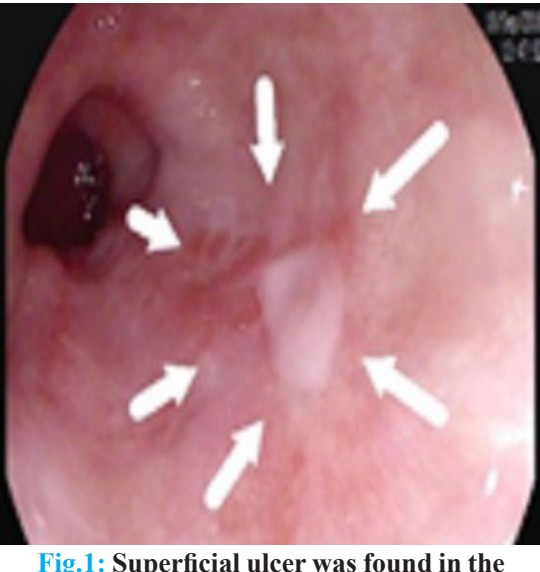

Fig.1: Superficial ulcer was found in the mid esophagus.

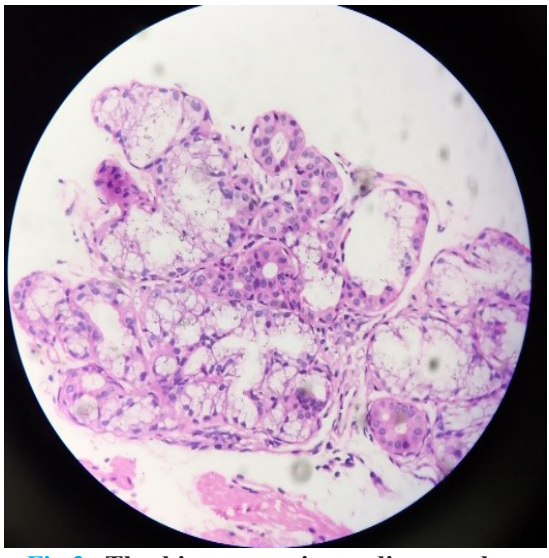

Fig.2: The biopsy specimen diagnosed as pancreatic rest containing both acini and ducts $\left(\mathrm{x}^{400}\right)$.

\section{DISCUSSION}

Heterotopic pancreatic tissue, which occurs most commonly in the stomach and duodenum, appears endoscopically as a submucosal lesion that usually contains a central umbilication. Unless the pancreatic rest be large, the upper gastrointestinal series is usually normal. Histologically, the tissue may contain acini, islets, and ducts. Patients do not usually develop symptoms from this entity, which is typically found during the evaluation of unrelated complaints. If symptoms develop, they are most likely secondary to a mass effect. Large lesions may cause obstruction, ulceration, hemorrhage, or intussusception. Other complications include pancreatitis, pseudocyst formation, carcinomas, islet-cell tumors, or inflammatory pseudotumors. Surgical excision is the only therapeutic option. . $^{1,2,3}$

Ectopic pancreatic tissue in the esophagus has been reported only 10 times in the literature and three of them were in patients younger than 18 years old. In those children, the ectopic tissue was associated with one or more anatomic abnormalities of the esophagus. ${ }^{3}$ One patient had a tracheoesophageal fistula, esophageal atresia, and esophageal duplication. ${ }^{5}$ The other two patients had a congenital diverticulum and a congenital cyst. ${ }^{6,7}$ Pancreatic rest was found in the distal third of the esophagus in six out of the 10 patients. In two adult patients, the lesion was found to be malignant. Nine patients underwent resection or enucleation of the lesion and one patient was followed up by observation. ${ }^{3}$

The prevalence of malignant transformation of heterotopic pancreatic tissue is unknown. Guillou and colleagues proposed that a carcinoma should be stated to originate from heterotopic pancreatic tissue only when the following three conditions are met: the tumor is found within or close to the ectopic pancreatic tissue; a direct transition between the pancreatic structures and the carcinoma can be shown (eg, duct cell dysplasia); and the non-neoplastic pancreatic tissue contains fully developed acini and ductal structures. ${ }^{8}$ The patient described above did not have any anatomic abnormalities and as there was no endoscopic or histological evidence of neoplasia, the suppressive therapy with pancreatic enzymes was planned and during his follow-up, all the patient's symptoms were completely resolved.

\section{ETHICAL APPROVAL}

There is nothing to be declared.

\section{CONFLICT OF INTEREST}

The authors declare no conflict of interest related to this work.

\section{REFERENCES}

1. Qualia CM, Rossi TM, Ullah A. Heterotopic pancreatic tissue found in the esophagus of a 14-year-old girl. Gastroenterol Hepatol (N Y) 2007;3:939-40.

2. Maisonnette F, Abita T, Lachachi F, Pichon N, DurandFontanier S, Valleix D, et al. Aberrant pancreas: report of five cases. Ann Chir 2004;129:241-3. doi: 10.1016/j.anchir.2004.01.015.

3. Temes RT, Menen MJ, Davis MS, Pett SB Jr, Wernly JA. Heterotopic pancreas of the esophagus 
masquerading as Boerhaave's syndrome. Ann Thorac Surg 2000;69:259-61. doi: 10.1016/s00034975(99)01223-0.

4. Noffsinger AE, Hyams DM, Fenoglio-Preiser CM. Esophageal heterotopic pancreas presenting as an inflammatory mass. Dig Dis Sci 1995;40:2373-9. doi: $10.1007 / \mathrm{bf02063240.}$

5. Ishikawa O, Ishiguro S, Ohhigashi H, Sasaki Y, Yasuda $\mathrm{T}$, Imaoka S, et al. Solid and papillary neoplasm arising from an ectopic pancreas in the mesocolon. Am J Gastroenterol 1990;85:597-601.

6. Chatterjee PH, Chatterjee SN, Dastidar N, Basu AK. Heterotopic gastric mucosa and pancreatic tissue in congenital diverticulum of esophagus. Indian J Surg 1982;44:139-41.

7. Roshe J, Del Buono E, Domenico D, Colturi TJ. Anaplastic carcinoma arising in ectopic pancreas located in the distal esophagus. J Clin Gastroenterol 1996;22:242-4. doi: 10.1097/00004836-19960400000022.

8. Guillou L, Nordback P, Gerber C, Schneider RP. Ductal adenocarcinoma arising in a heterotopic pancreas situated in a hiatal hernia. Arch Pathol Lab Med 1994;118:568-71. 